\title{
Monitoring the redox status in dairy cows by using plasma dROMs, PAT, and OSI biomarkers
}

\author{
Péter Hejel, Viktor Jurkovich, Barbara Bognár, Péter Kovács, Endre Brydl, László Könyves \\ University of Veterinary Medicine, Department of Animal Hygiene, Herd-health and Mobile Clinic, \\ Budapest, Hungary
}

Received June 23, 2020

Accepted May 26, 2021

\begin{abstract}
The aim of this work was to determine the changes of redox indicators such as reactive oxygen metabolites (dROMs), plasma antioxidant test (PAT) and the oxidative stress index (OSI) in dairy cows at different stages of lactation using a diagnostic equipment which is suitable for in vivo oxidative stress (OS) monitoring procedures. In total, 628 dairy cows were examined in the pre-parturient period (days in milk [DIM]: -21 to -1 day; $n=117$ ), in the calving and maternity period (DIM: 0 to $7 ; \mathrm{n}=137$ ), in the early lactation period (DIM: 8 to $30 ; \mathrm{n}=139$ ), and the in the peak lactation (DIM: 31 to $150 ; \mathrm{n}=235$ ). The dROMs and OSI values were significantly different $(P<0.05)$ when comparing the $1^{\text {st }}$ and $2^{\text {nd }}+$ lactation cows in each group. The highest mean value of dROMs was detected at the calving and maternity stage in $1^{\text {st }}$ lactation cows (141 $\pm 25 \mathrm{U}$. Carr $)$ and the lowest $(103 \pm 29$ U. Carr) was found in peak lactation. The OSI developed similarly, with the highest value of $5.58 \pm 0.94$ in the calving and maternity period in the $1^{\text {st }}$ lactation cows and the lowest value of $4.05 \pm 1.21$ in peak lactation and significant differences were found in many cases. Based on the results, the measurement of dROMs and OSI may be suitable for detecting oxidative stress in different lactation stages.
\end{abstract}

\section{Oxidative stress, reactive oxygen metabolites, cattle}

For the maintenance of health functions of a living organism it is necessary, that the amount of Reactive Oxygen Species (ROS) produced by the body or originated from external sources, should not exceed the protective capacity of the natural antioxidant (AO) defence mechanisms. Once if this balance is upset and ROS cannot be eliminated by the AO defence systems anymore, the oxidative stress (OS) develops leading to cell damage and finally resulting in reduced animal productivity (Sies et al. 1985). Previous studies have revealed the association of OS with diseases and health disorders in cattle, such as retained foetal membranes, metritis, mastitis (Kankofer et al. 1996), udder oedema (Miller et al. 1993; Celi, 2010; Jóźwik et al. 2012; Talukder et al. 2014), disturbances in energy metabolisms including insulin resistance (Pedernera et al. 2010; Xu et al. 2014; Mikulková et al. 2020), infertility, early embryonic death, development of follicular cysts (Miller et al. 1993; Rizzo et al. 2007, 2009; Celi et al. 2012) in cattle. There are several factors that may predispose to the development of OS, such as metabolic stress (Pastorelli et al. 2013), heat stress (Bernabucci et al. 2002; Lacetera et al. 2003; Zimbelman and Collier 2011), consumption of mycotoxin contaminated feeds and unregulated inflammatory processes (Miller et al. 1993). There are some physiological predisposing factors for OS, such as calving and birth (Castillo et al. 2005; Gaál et al. 2006; Albera and Kankofer 2011). However, based on previous experiences, most of the predisposing factors can be reduced by improved housing, nutrition- and animal health management (Dobbelaar et al. 2010). For measuring the effects of these improvements on herd-level prevalence of OS, the OS itself must be recognized as early as possible in time.

Address for correspondence:

Péter Hejel

University of Veterinary Medicine

Department of Animal Hygiene

Herd-Health and Mobile Clinic

István Street 2, 1078 Budapest, Hungary

Phone: +36309706005

Fax: hejel.peter@univet.hu

http://actavet.vfu.cz/ 
For indirect detection of OS, measurement of efficiency level of AO-defence system through glutathione-peroxidase (GPx), oxidised glutathione (GSSG), glutathione and GSSG ratio (GSH/GSSG), superoxide dismutase (SOD) activity is frequently used in research (Mikulková et al. 2019). The most direct OS biomarkers as malondialdehyde (MDA), thiobarbituric acid reactive substances (TBARS), F2-isoprostane, Oxygen radical absorbance capacity (ORAC), ferric reducing ability of plasma (FRAP), trolox equivalent antioxidant capacity (TEAC), radical-trapping antioxidant potential (TRAP), measured frequently for the detection of OS are not suitable for routine cow side monitoring purpose, because of relatively high costs and/or require special laboratory background (Celi 2011). There are needs for feasible methods for the evaluation of redox status of cows, that could be applicable in herd level OS monitoring protocols in farm conditions (Píšt'ková et al. 2019).

An equipment (FRAS 4 Evolvo; Free Radical Analytical System, H\&D s.r.l., Parma, Italy) was developed and has already been involved in several studies on OS in humans (Kanaoka et al. 2010; Serena et al. 2013) and other animal species (Celi 2010; Celi et al. 2010; Po et al. 2013) for research. Tests have also been carried out in cattle herds (Rizzo et al. 2007; Celi et al. 2011, 2012; Golder et al. 2016), but to our best knowledge, ranges of normal values for this species have not been reported yet. In the absence of these data, the usability of the device is limited, so we determined the mean value and standard deviation of primi- and multiparous cows in different lactation stages. These data may provide the basis for definition of reference intervals.

The medical term of reference interval for a test is based on the results that are seen in $95 \%$ of the healthy population. Calculation method of reference intervals mainly based on the statistical distribution of data. In case, if data show a normal (Gaussian) distribution, the reference range calculation formula is mean $\pm 2 \mathrm{SD}$. In case when distribution of data is not normal, a non-parametric statistical method can be applied for estimation of reference intervals according to International Federation of Clinical Chemistry (IFCC) recommendation. In this case, the lowest and highest $2.5 \%$ of data are simply excluded and remained data between 2.5 and 97.5\% means the reference interval (PetitClerc and Solberg 1987; Bland 2000; Szabó and Vásárhelyi 2015).

\section{Materials and Methods}

Data collection

Within the course of regular herd health and metabolic profile monitoring, 40 Hungarian large-scale dairy herds (248-2841/cow/farm) were visited between March 2017 and April 2019 (Plate I, Fig. 1).

Blood samples $(\mathrm{n}=628)$ were collected from dairy cows in the prepartum (PreP; Days in Milk (DIM): -21 to 1 day; $n=117)$, in the calving and maternity (Calv; DIM: 0 to $7 ; n=137)$, in the early lactation (EarlyL; DIM: $8-30 ; n=139)$ and in the peak lactation (PeakL; DIM: $31-150 ; n=235$ ) periods.

All of the included animals were clinically healthy and there was no disease or health issue reported in the previous two weeks according to the American Society for Veterinary Clinical Pathology (ASVCP) guideline (Friedrichs et al. 2012). Since some metabolic indicators were also determined, animals whose plasma concentration of $\beta$-hydroxybutyrate, non-esterified fatty acids and plasma enzyme activity of aspartate aminotransferase were out of the reference range $(>1.3 \mathrm{mmol} / 1 ;>0.3 \mathrm{mmol} / 1$ one to 21 days prepartum or $>0.6 \mathrm{mmol} / 1$ postpartum; and $>78 \mathrm{U} / 1$, respectively), were excluded from our study (Radostits et al. 2007; Ospina et al. 2010a; Ospina et al. 2010b). Disorders of energy metabolism (ketosis, extended fat mobilisation, or fatty liver) induce metabolic stress which is one of the major predisposing factors for development of OS (Sordillo and Mavangira 2014).

The animals were housed in a loose housing system and were fed ad libitum in a similar manner by total mixed rations (TMR) according to National Research Council (NRC) guidelines (Clark 2001).

The sampling took place 3 to $5 \mathrm{~h}$ after the morning feeding. The animals were only restrained for the sampling at the treatment stalls for a maximum of $30 \mathrm{~min}$. Blood samples $(10 \mathrm{ml})$ were taken from the milk vein (vena epigastrica superficialis) into heparinized (sodium heparin) glass tubes, using a single-use $15 \mathrm{G} \times 1 \frac{1 / 2}{2}$ " needle. Samples were immediately cooled to $4^{\circ} \mathrm{C}$ and transported to the laboratory.

Sample analysis

Sample analysis was performed within 12-24 h after sampling according to the manufacturer's guidelines (H\&D 2015). 
For measurement of reactive oxygen metabolites (d-ROMs), the blood sample was centrifuged by the instrument with 6000 RPM for $90 \mathrm{~s}$. Then, $10 \mu \mathrm{l}$ of plasma were mixed with chromogen reagent "R2" (iron solution, N, $\mathrm{N}$-diethyl-paraphenylendiamine) for $10 \mathrm{~s}$ and then filled into a provided cuvette in which the transition metal ion formed catalysed the hydroperoxide decomposition, generating new radical species, such as hydroperoxyl and alkoxyl radicals according to which it became possible to quantify the amount of hydroperoxides available in the sample by a photometric reading on $505 \mathrm{~nm}$. Then the mixture was inserted into the reader cell of the instrument. The reading process was undertaken for $300 \mathrm{~s}$, then the dROMs result was displayed.

For testing the plasma antioxidant capacity (PAT) concentration, $40 \mu \mathrm{l}$ of "R2" were added to the cuvette containing the reagent "R1" (thiocyanate derivate pre-dosed solution). Following calibration, $10 \mu \mathrm{l}$ of plasma were added and mixed. The reading was taken after $60 \mathrm{~s}$ at $505 \mathrm{~nm}$.

The results of the measurements were stored in Microsoft Excel datasheets (Microsoft Corporation, Redmond, USA).

\section{Statistical analysis}

The data analysis was performed by using R Statistical Program version 3. 3. 1. (R Core Team, 2018). Normal distribution of data was confirmed by Saphiro-Wilk test (Figs 2-4). Following the descriptive statistics, the variance of means and standard deviations (SD) were compared among groups with ANOVA and Tukey post hoc tests.
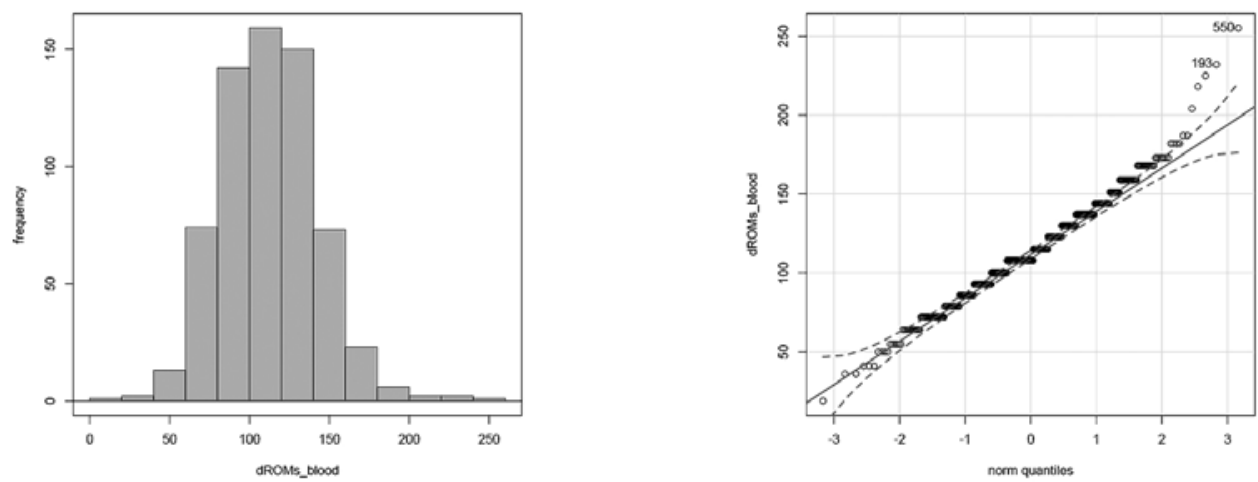

Fig 2. Statistical distributions of reactive oxygen metabolites (d-ROMs) values (Saphiro-Wilk test $P<0.0001)$
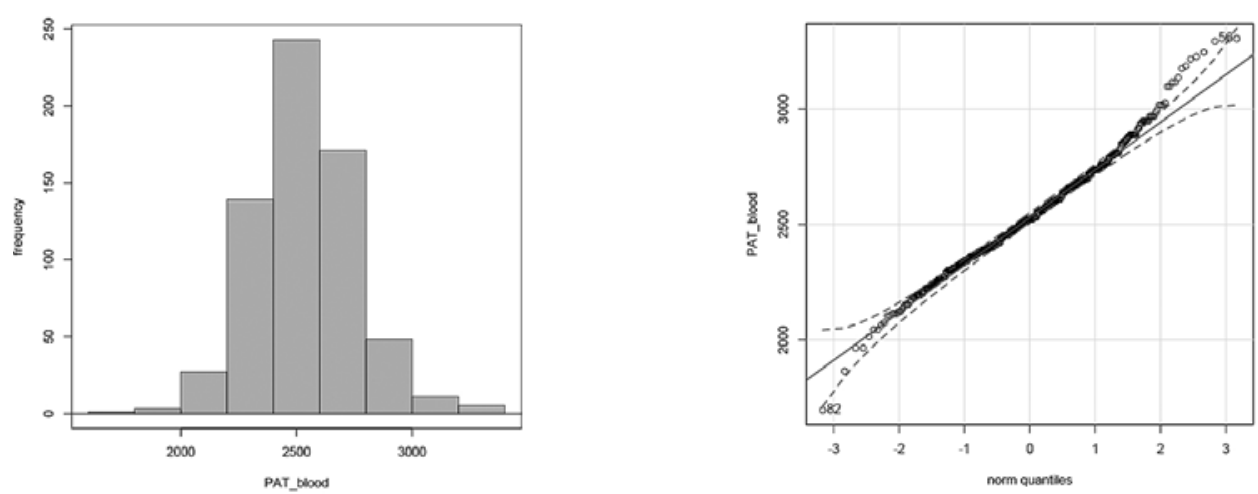

Fig 3. Statistical distributions of plasma antioxidant capacity (PAT) values (Saphiro-Wilk test $P<0.0001$ ) 

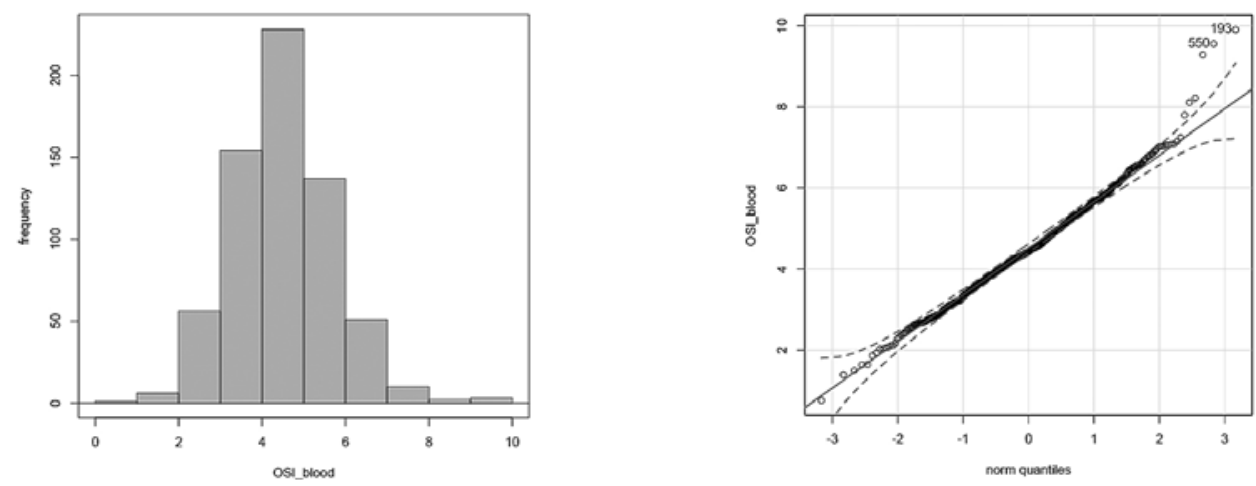

Fig 4. Statistical distributions of the oxidative stress index (OSI) values (Saphiro-Wilk test $P<0.0001$ )

\section{Results}

The distribution of dROMs, PAT, and OSI data was tested for normality by Saphiro-Wilk test and showed normal distribution $(P<0.0001)$ (Figs $2-4)$. The mean $\pm \mathrm{SD}$ of dROMs, PAT, and OSI values are shown in Table 1 . Data were also analysed according to the parity. The values of cows in the first lactation $(\mathrm{n}=195)$ and in the second and further lactations $(\mathrm{n}=433)$ were significantly different $(P<0.05)$ (Tables 2 and 3$)$. Therefore, further comparisons of the groups were performed in both age groups. There was a significant difference $(P<0.05)$ between the dROMs and OSI mean values for each group, whereas the difference in PAT values was not supported by statistical tests in any of the cases (Table 4).

The study period covered all four seasons, so we compared the summer data with the combined data for spring, autumn, and winter (Table 5), but we did not find any significant associations or differences.

Reference intervals for different groups were calculated using the formula mean $\pm 2 \mathrm{SD}$ due to the fact that they showed a normal statistical distribution (Figs 2-4) (PetitClerc and Solberg 1987; Bland 2000; Szabó and Vásárhelyi 2015). The calculated ranges of each observed group are shown in Table 6.

Table 1. The mean and standard deviation (SD) of redox indicators in each group.

\begin{tabular}{lcccc}
\hline Grops/OS markers & PreP $(\mathrm{n}=117)$ & Calv $(\mathrm{n}=137)$ & EarlyL $(\mathrm{n}=139)$ & PeakL $(\mathrm{n}=235)$ \\
\hline dROMs (U. Carr) mean \pm SD & $112 \pm 23$ & $133 \pm 31$ & $114 \pm 28$ & $104 \pm 28$ \\
PAT (U. Cor) mean \pm SD & $2533 \pm 256$ & $2520 \pm 205$ & $2550 \pm 240$ & $2538 \pm 187$ \\
OSI mean \pm SD & $4.44 \pm 0.89$ & $5.30 \pm 1.23$ & $4.48 \pm 1.16$ & $4.10 \pm 1.11$ \\
\hline
\end{tabular}

PreP - preparturient cows; Calv - cows in calving and maternity; EarlyL - cows in early lactation; PeakL - cows in peak lactation; dROMs - reactive oxygen metabolites; PAT - plasma antioxidant capacity; OSI - oxidative stress index

Table 2. The mean and standard deviation (SD) of redox indicators in different age classes.

\begin{tabular}{lccr}
\hline OS markers/parity & First lactation $(\mathrm{n}=195)$ & Second + lactation $(\mathrm{n}=433)$ & $P$ value \\
\hline dROMs (U. Carr) mean \pm SD & $119 \pm 30$ & $112 \pm 29$ & 0.0184 \\
PAT (U. Cor) mean \pm SD & $2539 \pm 197$ & $2541 \pm 219$ & 0.99 \\
OSI mean \pm SD & $4.71 \pm 1.24$ & $4.42 \pm 1.16$ & 0.0132 \\
\hline
\end{tabular}

dROMs - reactive oxygen metabolites; PAT - plasma antioxidant capacity; OSI - oxidative stress index 
Table 3. Comparison of differences of the mean values (mean \pm standard deviation; SD) of redox indicators in each group.

\begin{tabular}{|c|c|c|c|c|c|c|c|c|}
\hline & $\begin{array}{l}\text { PreP } 1^{\text {st }} \\
(n=42)\end{array}$ & $\begin{array}{l}\text { PreP } 2^{\text {nd }}+L \\
\quad(n=75)\end{array}$ & $\begin{array}{l}\text { Calv } 1^{\text {st }} \mathrm{L} \\
(\mathrm{n}=47)\end{array}$ & $\begin{array}{c}\text { Calv } 2^{\text {nd }}+\mathrm{L} \\
(\mathrm{n}=90)\end{array}$ & $\begin{array}{c}\text { EarlyL } 1^{\text {st }} \mathrm{L} \\
\quad(\mathrm{n}=48)\end{array}$ & $\begin{array}{l}\text { EarlyL } 2^{\text {nd }}+L \\
\quad(n=91)\end{array}$ & $\begin{array}{c}\text { PeakL 1 } \\
(\mathrm{n}=58)\end{array}$ & $\begin{array}{c}\text { PeakL } 2^{\text {nd }}+L \\
(n=177)\end{array}$ \\
\hline \multicolumn{9}{|l|}{$\overline{\mathrm{dROMs}}$} \\
\hline $\begin{array}{l}\text { mean } \pm \mathrm{SD} \\
\text { (U. Carr) }\end{array}$ & $114(22)$ & $112(23)$ & $141(25)$ & $129(33)$ & $121(31)$ & 109 (27) & $103(29)$ & $104(27)$ \\
\hline$P$ value & 0.844 & & 0.0357 & & 0.0358 & & 0.768 & \\
\hline $\begin{array}{l}\text { PAT } \\
\text { mean } \pm \text { SD } \\
\text { (U. Cor) }\end{array}$ & $2514(202)$ & $2554(275)$ & $2523(194)$ & $2522(214)$ & $2542(229)$ & $2567(243)$ & 2549 (188) & $2531(184)$ \\
\hline$P$ value & 0.869 & & 0.983 & & 0.581 & & 0.536 & \\
\hline $\begin{array}{l}\text { OSI } \\
\text { mean } \pm \text { SD }\end{array}$ & $4.57(0.88)$ & $4.43(0.90)$ & $5.58(0.94)$ & $5.14(1.31)$ & $4.79(1.29)$ & $4.28(1.08)$ & $4.05(1.21)$ & $4.10(1.06)$ \\
\hline$P$ value & 0.756 & & 0.0414 & & 0.0232 & & 0.764 & \\
\hline
\end{tabular}

- preparturient cows; Calv - cows in calving and maternity; EarlyL - cows in early lactation; PeakL - cows in peak lactation; L - lactation; dROMs - reactive oxygen metabolites; PAT - plasma antioxidant capacity; OSI - oxidative stress index

Table 4. Differences in the values of redox indicators between the groups.

\begin{tabular}{lcrrrrr}
\hline & \multicolumn{2}{c}{} & \multicolumn{2}{c}{$P$ value } & & OSI \\
\cline { 2 - 7 } & \multicolumn{2}{c}{ dROM } & \multicolumn{2}{c}{ PAT } & $1^{\text {st }} \mathrm{L}$ & $2^{\text {nd }}+\mathrm{L}$ \\
\hline PreP vs Calv & $<0.01$ & $<0.001$ & 0.979 & 0.794 & $<0.001$ & $<0.001$ \\
PreP vs EarlyL & 0.74561 & 0.908 & 1.000 & 0.984 & 0.72477 & 0.845 \\
PreP vs PeakL & 0.13320 & 0.112 & 0.997 & 0.878 & 0.15873 & 0.136 \\
Calv vs EarlyL & 0.00264 & $<0.001$ & 0.965 & 0.574 & 0.00334 & $<0.001$ \\
Calv vs PeakL & $<0.001$ & $<0.001$ & 0.913 & 0.989 & $<0.001$ & $<0.001$ \\
EarlyL vs PeakL & 0.00424 & 0.489 & 0.998 & 0.654 & 0.00517 & 0.655 \\
\hline
\end{tabular}

PreP - preparturient cows; Calv - cows in calving and maternity; EarlyL - cows in early lactation; PeakL - cows in peak lactation; L - lactation; dROMs - reactive oxygen metabolites; PAT - plasma antioxidant capacity; OSI oxidative stress index

Table 6. Estimated reference intervals of the values of redox indicators (mean \pm standard deviation; SD).

\begin{tabular}{|c|c|c|c|c|c|c|}
\hline & $\begin{array}{c}\text { PreP } \\
(\mathrm{n}=117)\end{array}$ & $\begin{array}{c}\text { Calv } 1^{\text {st }} \mathrm{L} \\
(\mathrm{n}=47)\end{array}$ & $\begin{array}{l}\text { Calv } 2^{\text {nd }}+\mathrm{L} \\
(\mathrm{n}=90)\end{array}$ & $\begin{array}{c}\text { EarlyL } 1^{\text {st }} \mathrm{L} \\
(\mathrm{n}=48)\end{array}$ & $\begin{array}{l}\text { EarlyL } 2^{\text {nd }}+L \\
\quad(n=91)\end{array}$ & $\begin{array}{c}\text { PeakL } \\
(\mathrm{n}=235)\end{array}$ \\
\hline $\begin{array}{l}\text { dROMs } \\
(\text { mean } \pm \text { SD; U. Carr) }\end{array}$ & $112(23)$ & $141(25)$ & $129(33)$ & $121(31)$ & $109(27)$ & $104(28)$ \\
\hline Reference interval & $68-158$ & $91-191$ & $63-195$ & $59-183$ & $55-163$ & $48-160$ \\
\hline $\mathrm{OSI}($ mean $\pm \mathrm{SD})$ & $4.44(0.89)$ & $5.58(0.94)$ & $5.14(1.31)$ & $4.79(1.29)$ & $4.28(1.08)$ & $4.10(1.11)$ \\
\hline Reference interval & $2.64-6.22$ & $3.70-7.46$ & $2.52-7.76$ & $2.21-7.37$ & $2.12-6.44$ & $1.88-6.32$ \\
\hline $\begin{array}{l}\text { PAT } \\
(\text { mean } \pm \mathrm{SD} \text {; U. Cor) }\end{array}$ & $2533(256)$ & $2523(194)$ & 2522 214) & $2542(229)$ & $2567(243)$ & $2538(187)$ \\
\hline Reference interval & $2021-3045$ & $2135-2911$ & 2094-2950 & 2084-3000 & $2081-3053$ & $2164-2912$ \\
\hline
\end{tabular}

PreP - preparturient cows; Calv - cows in calving and maternity; EarlyL - cows in early lactation; PeakL - cows in peak lactation; L - lactation; dROMs - reactive oxygen metabolites; PAT - plasma antioxidant capacity; OSI - oxidative stress index 


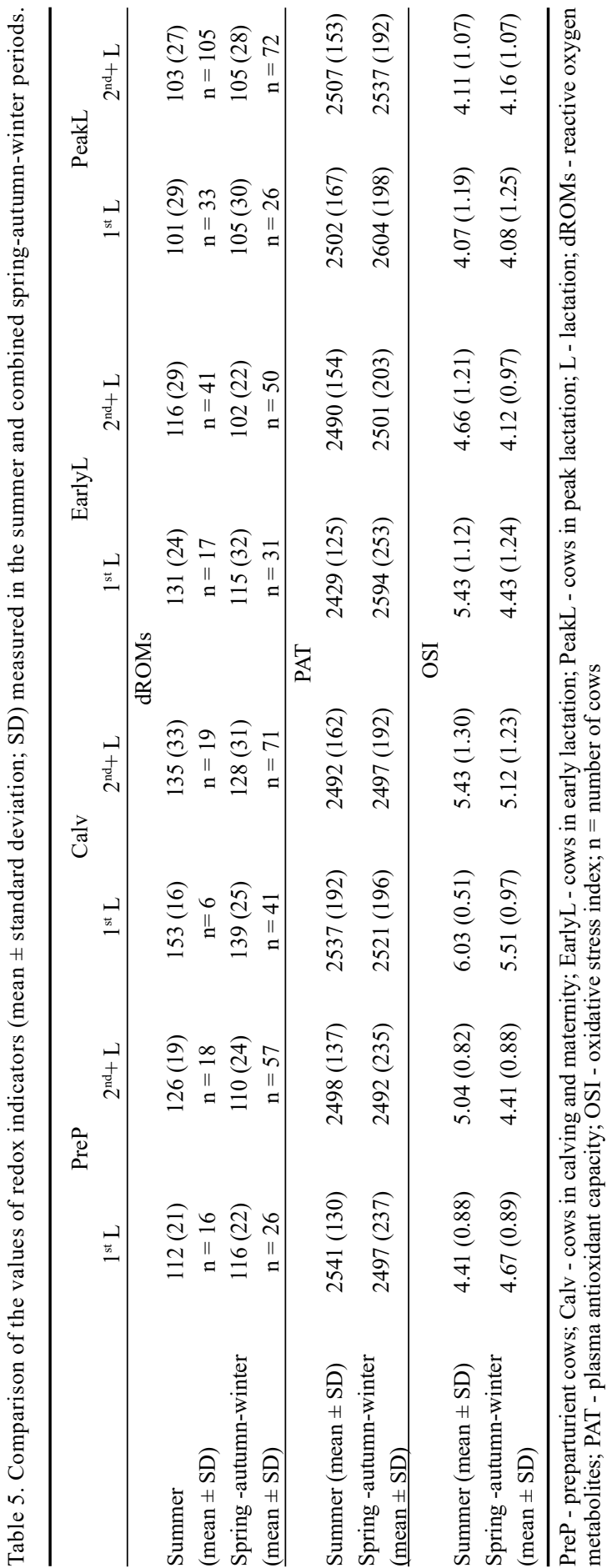

\section{Discussion}

The periparturient period is very challengeful for dairy cows and as a result, most of the metabolic disorders and also infectious diseases may occur within the first few weeks of lactation (Goff and Horst 1997). Strong evidence has been reported on the role that OS plays in the initiation, progression, and maintenance of these pathological cases (Abuelo et al. 2013).

Once the redox-homeostasis of the body is disturbed, malicious cell-damaging processes may develop and jeopardize the general health and productivity (Abuelo et al. 2015). This challenge frequently occurs in the early lactation in dairy cows, when the energy balance is negative (Sordillo and Aitken 2009). For compensation, the energy-producing metabolism is becoming more intensive, finally resulting in higher ROS formation. However, based on the results, this does not seem to be the riskiest period in terms of OS. Even though slight elevation of dROMs was detected (121 \pm 31 and $109 \pm 27$ U. Carr) in the first lactation and multiparous early lactation cow groups, respectively, they did not differ significantly $(P>0.05)$ from the data of the preparturient period (114 \pm 22 and $112 \pm 23$ U. Carr) in the first lactation and multiparous cows, respectively (Table 1). The dROMs data recorded in fresh cow groups were significantly different $(P<0.01)$ from data in the calving and maternity period, and from data in the peak yielding cows $(P<0.01)$.

We found the period near around calving to be the most endangered by OS, when the 
highest dROMs and OSI values were recorded at this time in both primi- and multiparous cows (dROMs: $141 \pm 25$ and $129 \pm 33$ U. Carr, respectively; OSI: $5.58 \pm 0.94$ and $5.14 \pm 1.31$, respectively). These results are similar to Píšt'ková et al. (2019) who also found very apparent signs of OS in 2-3 days postpartum in dairy cows. In this period, they recorded a significant decrease in the total antioxidant status, vitamin $\mathrm{A}$ and $\mathrm{E}$ concentration and $\beta$-carotene, while the GPx and SOD activity were increased. The pattern of dROMs values in the near to calving period we found are also similar to others' findings (Abuelo et al. 2013) who reported 153 U. Carr in the group until 1 month after calving and also detected a decline in the peak lactation stage (145.1 U. Carr). However, they found the highest dROMs levels in the prepartum (-1 month to calving) period, whereas we found low values at that stage. Their results are generally higher than ours in all observed lactation stages. They studied fewer $(n=22)$ healthy cows, but the main difference was in the methodology, in that they measured dROMs from serum, whereas we did that from heparinized plasma which may explain the difference.

The elevated ROS values are clearly associated with calving and they can trigger the development of OS in cows (Castillo et al. 2005; Gaál et al. 2006; Albera and Kankofer 2011). Increased activity of mitochondria is detectable in human females during pregnancy being linked with increased metabolism, which may lead to ROS overproduction (Wisdom et al. 1991; Albera and Kankofer 2011). This process may be similar in other species as well. It has been reported that BCS correlates with these indicators and may influence the level of oxidative processes in cows during the periparturient period (Mikulková et al. 2020). This finding supports the assumption that peripartum energy disbalance may predispose to the development of OS. The physical stress related to the delivery of foetus may contribute to metabolic reactions resulting in overproduction of ROS (Miller et al. 1993; Albera and Kankofer 2011). The lipid-peroxidation is growing more intensive around parturition in the cows (Castillo et al. 2005), and the start of respiration may result in elevated ROS formation in new born calves (Covarrubias et al. 2008; Halliwell and Gutteridge 2015).

The intensive development of the mammary gland and the onset of colostrum and milk secretion may overwhelm the female body. The cow uses a remarkable amount of AOs for colostrum production (Goff and Horst 1997). As a consequence, the decreased concentration of major AO such as vitamins $\mathrm{A}$ and $\mathrm{E}$ has also been observed at parturition (Goff and Stabel 1990). Consequently, the AO defence capacity may be lower than ROS production.

All of these actions may predispose the body for development of OS in the periparturient period and may explain why the highest dROMs and OSI values were detectable in the first few days of lactation.

The lowest dROMs $(103 \pm 29$ and $104 \pm 27$ U. Carr in first-parity and multiparous cows, respectively) and OSI values (4.05 \pm 1.21 and $4.10 \pm 1.06$ in first-parity and multiparous cows, respectively) were in the peak production stage of the lactation. Our finding is in accordance with earlier results, and the metabolic status seems to be more stable as manifested in a better AO status when the animal reaches peak lactation (Castillo et al. 2006; Konvičná et al. 2015).

Heat stress may elevate ROS production (Sordillo and Raphael 2013). We did not find any significantly consistent trend when comparing the data originated from the summer and other seasons (Table 5). However, our current study was not designed to investigate the effects of heat stress on OS.

Since statistically detectable differences in dROMs and OSI values were found for each lactation period during comparison of calving and maternity periods with others, it was considered appropriate to define reference ranges accordingly. This is to draw attention to the fact that when interpreting the measured values, attention must be paid to the physiological state and lactation. 
The PAT biomarker did not show any significant difference among the observed lactation stages in our study. We did not research the question why PAT did not show a reasonable difference in the observed groups; however, it is an exciting and motivating point for further research.

Based on the mean values of significant differences shown in the dROMs and OSI values we established the reference intervals for these indices (Table 6). Although there are publications available directed to determine the reference ranges of biochemical indices, in which the requirement for inclusion of animals was being clinically healthy (Lumsden et al. 1980; Kusano et al. 2016), since we had the opportunity to investigate some relevant indicators of energy metabolism (BHB, NEFA, and AST) from the same samples, we decided to exclude from the study those animals whose values were out of the normal range because metabolic stress is one of the major predisposing factors in development OS.

We calculated the reference intervals for all groups that showed significant differences, hence our data might be overdetailed from a clinical point of view, however, it is reasonable to show the details from scientific aspects.

\section{Acknowledgements}

The project was supported by the European Union and co-financed by the European Social Fund (grant agreement number: EFOP-3.6.2-16-2017-00012, project title: Development of a Product Chain Model for Functional, Healthy and Safe Foods from Farm to Fork Based on a Thematic Research Network; and grant agreement number: EFOP-3.6.1-16-2016-00024, project title: Institutional Developments for Intelligent Specialization in co-operation of the University of Veterinary Medicine and the Faculty of Agricultural and Food Sciences, Széchenyi István University).

\section{References}

Abuelo A, Hernández J, Benedito JL, Castillo C 2013: Oxidative stress index (OSi) as a new tool to assess redox status in dairy cattle during the transition period. Animal 7: 1374-1378

Abuelo A, Hernández J, Benedito JL, Castillo C, Hernández J, Benedito JL, Castillo C, Hernández J, Benedito JL, Castillo C 2015: The importance of the oxidative status of dairy cattle in the periparturient period: Revisiting antioxidant supplementation. J Anim Physiol An Nutr 99: 1003-1016

Albera E, Kankofer M 2011: The comparison of antioxidative/oxidative profile in blood, colostrum and milk of early post-partum cows and their newborns. Reprod Domest Anim 46: 763-769

Bernabucci U, Ronchi B, Lacetera N, Nardone A 2002: Markers of oxidative status in plasma and erythrocytes of transition dairy cows during hot season. J Dairy Sci 85: 2173-2179

Bland M 2000: An introduction to medical statistics, $3^{\text {rd }}$ edn. Oxford University Press, 448 p.

Castillo C, Hernandez J, Bravo A, Lopez-Alonso M, Pereira V, Benedito JL 2005: Oxidative status during late pregnancy and early lactation in dairy cows. Vet J 169: 286-292

Castillo C, Hernández J, Valverde I, Pereira V, Sotillo J, Alonso ML, Benedito JL 2006: Plasma malonaldehyde (MDA) and total antioxidant status (TAS) during lactation in dairy cows. Res Vet Sci 80: 133-139

Celi P 2010: The role of oxidative stress in small ruminants' health and production. R Bras Zootec 39: 348-363

Celi P 2011: Biomarkers of oxidative stress in ruminant medicine. Immunopharmacol Immunotoxicol 33: 233-240

Celi P, Merlo M, Barbato O, Gabai G 2012: Relationship between oxidative stress and the success of artificial insemination in dairy cows in a pasture-based system. Vet J 193: 498-502

Celi P, Merlo M, Dalt L Da, Stefani A, Barbato O, Gabai G 2011: Relationship between late embryonic mortality and the increase in plasma advanced oxidised protein products (AOPP) in dairy cows. Reprod Fert Develop 23: $527-533$

Celi P, Sullivan M, Evans D 2010: The stability of the reactive oxygen metabolites (d-ROMs) and biological antioxidant potential (BAP) tests on stored horse blood. Vet J 183: 217-218

Clark JH 2001: Requirements of Dairy Cattle. $7^{\text {th }}$ revised edn. National Academy Press, 2101 Constitution Avenue, NW., Washington D.C. 20418, USA

Covarrubias L, Hernández-García D, Schnabel D, Salas-Vidal E, Castro-Obregón S 2008: Function of reactive oxygen species during animal development: Passive or active? Dev Biol 320: 1-11

Dobbelaar P, Bouwstra RJ, Goselink RMA, Jorritsma R, Borne JJGC van den, Jansen EHJM 2010: Effects of vitamin $\mathrm{E}$ supplementation on and the association of body condition score with changes in peroxidative biomarkers and antioxidants around calving in dairy heifers. J Dairy Sci 93: 3103-3113 
Friedrichs KR, Harr KE, Freeman KP, Szladovits B, Walton RM, Barnhart KF, Blanco-Chavez J 2012: ASVCP reference interval guidelines: Determination of de novo reference intervals in veterinary species and other related topics. Vet Clin Path 41: 441-453

Gaál T, Ribiczeyné-Szabó P, Stadler K, Jakus J, Reiczigel J, Kövér P, Mézes M, Sümeghy L 2006: Free radicals, lipid peroxidation and the antioxidant system in the blood of cows and newborn calves around calving. Comp Biochem Physiol 143: 391-396

Goff JP, Horst RL 1997: Physiological changes at parturition and their relationship to metabolic disorders. J Dairy Sci 80: $1260-1268$

Goff JP, Stabel JR 1990: Decreased plasma retinol, $\alpha$-tocopherol, and zinc concentration during the periparturient period: effect of milk fever. J Dairy Sci 73: 3195-3199

Golder HM, Celi P, Takahashi J, Lean IJ 2016: Effect of ruminal mechanical stimulating brushes on rumen fermentation and plasma oxidative stress and subsequent milk yield and composition in lactating dairy cattle. Anim Prod Sci 57: 1-11

H\&D 2015: The Measurement of Oxidative Stress. http://www.hedsrl.it.

Halliwell B, Gutteridge JMC 2015: Free Radicals in Biology and Medicine. $5^{\text {th }}$ edn. Oxford University Press, Oxford, UK, 944 p.

Jóźwik A, Krzyżewski J, Strzałkowska N, Poławska E, Bagnicka E, Wierzbicka A, Niemczuk K, Lipińska P, Horbańczuk JO 2012: Relations between the oxidative status, mastitis, milk quality and disorders of reproductive functions in dairy cows-A review. Anim Sci Pap Rep 30: 297-307

Kanaoka Y, Inagaki E, Hamanaka S, Masaki H, Tanemoto K 2010: Analysis of reactive oxygen metabolites (ROMs) after cardiovascular surgery as a marker of oxidative stress. Acta Med Okayama 64: 323-330

Kankofer M, Podolak M, Fidecki M, Gondek T 1996: Activity of placental glutathione peroxidase and superoxide dismutase in cows with and with out retained fetal membranes. Placenta 17: 591-594

Konvičná J, Vargová M, Paulíková I, Kováč G, Kostecká Z 2015: Oxidative stress and antioxidant status in dairy cows during prepartal and postpartal periods. Acta Vet Brno 84: 133-140

Kusano K, Yamazaki M, Kiuchi M, Kaneko K, Koyama K 2016: Reference range of blood biomarkers for oxidative stress in Thoroughbred racehorses (2-5 years old). J Equine Sci Vol 27: 125-129

Lacetera N, Bernabucci U, Khalifa HH, Ronchi B, Nardone A 2003: Interactions between climate and animal production. EAAP Technical Series Vol. 7. The Netherlands, pp. 1-124

Lumsden JH, Mullen K, Rowe R 1980: Hematology and biochemistry reference values for female Holstein cattle. Can J Comp Med 44: 24-31

Mikulková K, Illek J, Bezděková Z, Šimková I 2019: Glutathione as an antioxidant marker: Determination of glutathione concentration in the breast muscles and liver of broilers supplemented with different selenium sources. Acta Vet Brno 88: 157-163

Mikulková K, Illek J, Kadek R 2020: Glutathione redox state, glutathione peroxidase activity and selenium concentration in periparturient dairy cows, and their relation with negative energy balance. J Anim Feed Sci 29: 19-26

Miller JK, Brzezinska-Slebodzinska E, Madsen FC 1993: Oxidative stress, antioxidants, and animal function. J Dairy Sci 76: 2812-2823

Ospina PA, Nydam DV, Stokol T, Overton TR 2010a: Association between the proportion of sampled transition cows with increased nonesterified fatty acids and $\beta$-hydroxybutyrate and disese incidence, pregnancy rate, and milk production at the herd level. J Dairy Sci 93: 3595-3601

Ospina PA, Nydam DV, Stokol T, Overton TR 2010b: Evaluation of nonesterified fatty acids and $\beta$-hydroxybutyrate in transition dairy cattle in the northeastern United States: Critical thresholds for prediction of clinical diseases. J Dairy Sci 93: 546-554

Pastorelli G, Faustini M, Corino C, Rossi R 2013: Kit Radicaux Libres, a new innovative biological application for monitoring oxidative stress in pigs. Ital J Anim Sci 12: 3, e70

Pedernera M, Celi P, García SC, Salvin HE, Barchia I, Fulkerson WJ 2010: Effect of diet, energy balance and milk production on oxidative stress in early-lactating dairy cows grazing pasture. Vet J 186: 352-357

PetitClerc C, Solberg H 1987: Approved recommendation (1987) on the theory of reference values. Part 2. Selection of individuals for the production of reference values. Clin Chim Acta 170: S3-S12

Píšt'ková K, Illek J, Kadek R 2019: Determination of antioxidant indices in dairy cows during the periparturient period. Acta Vet Brno 88: 3-9

Po E, Williams C, Muscatello G, Celi P 2013: Assessment of oxidative stress biomarkers in exhaled breath condensate and blood of thoroughbred foals. Vet J 196: 269-271

Radostits OM, Gay CC, Hinchcliff KW, Constable PD 2007: Veterinary Medicine - A textbook of the disease of cattle, sheep, goats, pigs and horses. $10^{\text {th }}$ edn. Sarne De Vliegher, Ghent-Belgium

Rizzo A, Minoia G, Trisolini C, Manca R, Sciorsci RL 2007: Concentrations of free radicals and beta-endorphins in repeat breeder cows. Anim Reprod Sci 100: 257-263

Rizzo A, Minoia G, Trisolini C, Mutinati M, Spedicato M, Jirillo F, Sciorsci RL 2009: Reactive oxygen species (ROS): involvement in bovine follicular cysts etiopathogenesis. Immunopharm Immunot 31: 631-635

Serena B, Primiterra M, Catalani S, Finco A, Canestrari F, Cornelli U 2013: Performance evaluation of the innovative PAT test, comparison with the common BAP test and influence of interferences on the evaluation of the plasma antioxidant capacity. Clin Lab 59: 1091-1097 
Sies H, Beckmann R, Brigelius R, Cadenas E, Clark IA, Cohen GC, Cowden WB, Evans CG, Flohé L, Frei B, Früstenberger G, Giertz H, Hamers MN, Jones DP, Kappus H, Loschen G, Marks F, Orrenius S, Reed DJ, Richter C, Roos D, Schulte-Frohlinde D, Smith MT, Stern A, Thor H, Sonntag C von, Wills ED, Willson RL 1985: Oxidative Stress. Academic Press Inc., London, 507 p.

Sordillo LM, Aitken SL 2009: Impact of oxidative stress on the health and immune function of dairy cattle. Vet Immunol Immunop 128: 104-109

Sordillo LM, Mavangira V 2014: The nexus between nutrient metabolism, oxidative stress and inflammation in transition cows. Anim Prod Sci 54: 1204-1214

Sordillo LM, Raphael W 2013: Significance of metabolic stress, lipid mobilization, and inflammation on transition cow disorders. Vet Clin N Am-food A 29: 267-278

Szabó A, Vásárhelyi B 2015: Bevezetés a laboratóriumi medicinába (in Hungarian: Introduction to Laboratory Medicine). $2^{\text {nd }}$ edn. Semmelweis Kiadó, Budapest, Hungary, $420 \mathrm{p}$.

Talukder S, Ingenhoff L, Kerrisk KL, Celi P 2014: Plasma oxidative stress biomarkers and progesterone profiles in a dairy cow diagnosed with an ovarian follicular cyst. Vet Quart 34: 113-117

Wisdom SJ, Wilson R, McKillop JH, Walker JJ 1991: Antioxidant systems in normal pregnancy and in pregnancyinduced hypertension. Am J Obstet Gynecol 165: 1701-1704

Xu C, Shu S, Xia C, Wang B, Zhang H 2014: Investigation on the relationship of insulin resistance and ketosis in dairy cows. J Veterinar Sci Technol 5: 1000162

Zimbelman RB, Collier RJ 2011: Feeding strategies for high-producing dairy cows during periods of elevated heat and humidity. In: Proceedings of Tri-State Dairy Nutrition Conference. Fort Wayne, IN, USA, pp. 111-126 
Plate I

Hejel P. et al.: Monitoring ... pp. 125-134

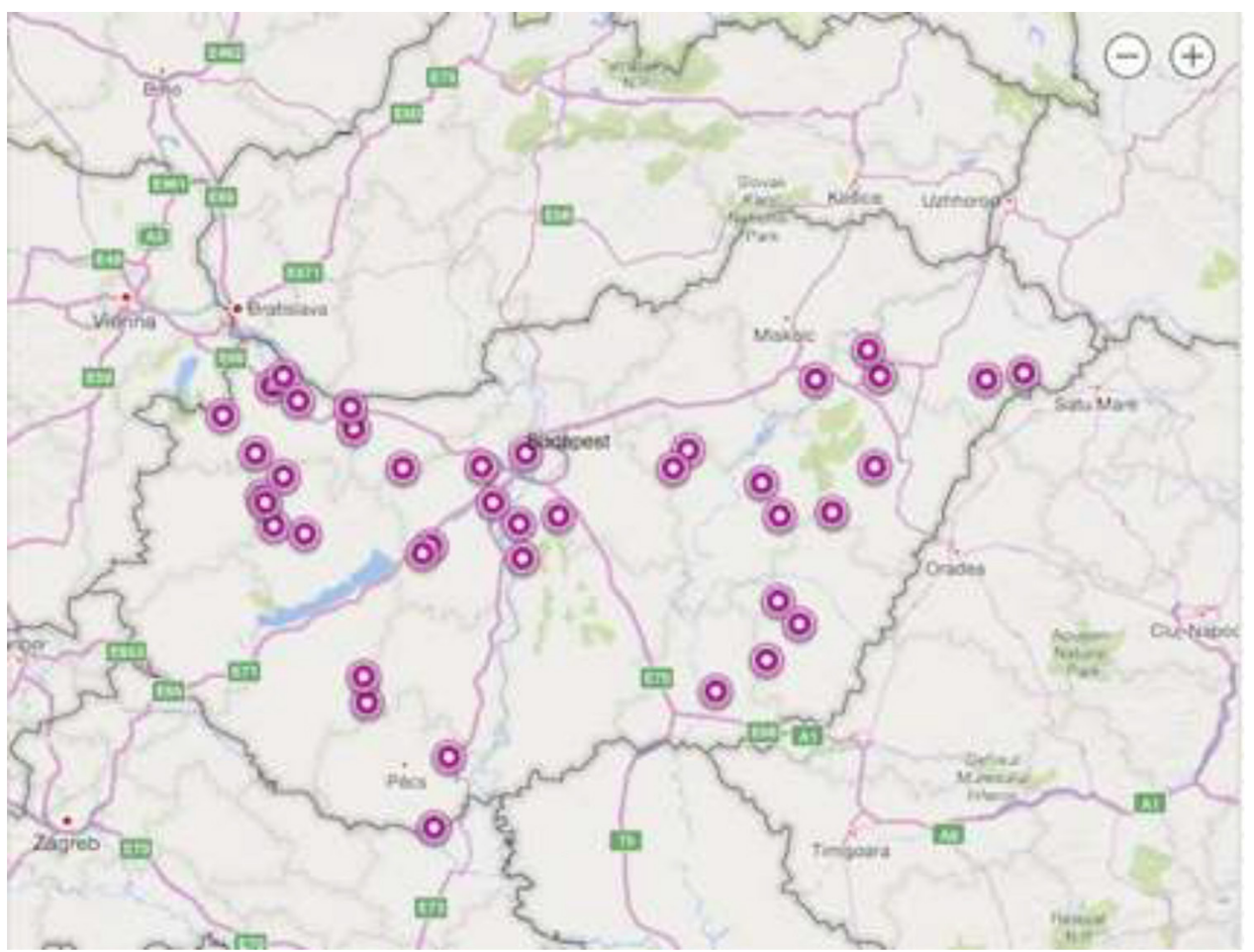

Fig 1. Locations of involved dairy farms 